This information is current as of April 26, 2023.

\title{
Imaging Characteristics of Recurrent Pleomorphic Adenoma of the Parotid Gland
}

G. Moonis, P. Patel, Y. Koshkareva, J. Newman and L.A. Loevner

AJNR Am J Neuroradiol 2007, 28 (8) 1532-1536

doi: https://doi.org/10.3174/ajnr.A0598

http://www.ajnr.org/content/28/8/1532 


\section{ORIGINAL RESEARCH}

G. Moonis

P. Patel

Y. Koshkareva

J. Newman

L.A. Loevner

\section{Imaging Characteristics of Recurrent Pleomorphic Adenoma of the Parotid Gland}

BACKGROUND AND PURPOSE: Pleomorphic adenoma is the most common parotid neoplasm. It has a relatively high rate of recurrence after surgery. Imaging features of recurrent parotid pleomorphic adenoma have been infrequently reported in the radiology literature. In the present study, we reviewed our institutional experience with imaging of recurrent parotid pleomorphic adenomas.

MATERIALS AND METHODS: Retrospective imaging and chart review of 24 patients ( 9 men, 15 women; age, 29-63 years) with recurrent pleomorphic adenoma of the parotid were performed. Images were reviewed as to the margins, site, multiplicity, signal intensity, and enhancement pattern of the recurrent lesions by 2 neuroradiologists.

RESULTS: We found a high incidence of multiple lesions in the operative bed, most of which were extremely bright on T2-weighted images; some of the lesions demonstrated a cystic appearance with peripheral enhancement. We also noted tiny lesions in the subcutaneous fat and in regions distant from the immediate operative bed.

CONCLUSION: Although recurrent disease is usually clinically apparent, sometimes prior surgical history is lacking or recurrence may be detected on routine surveillance imaging after initial surgery. The presence of solitary or multiple subcutaneous T2 hyperintense lesions in the operative bed, subcutaneous fat, and/or spaces adjacent to the parotid in patients with prior parotidectomy for pleomorphic adenoma is consistent with the diagnosis of neoplastic recurrence. The radiologist should maintain a high index of suspicion for recurrent pleomorphic adenoma with this characteristic imaging appearance.
$\mathbf{P}$ leomorphic adenoma, or benign mixed tumor, is the most common tumor of the parotid gland and represents $70 \%$ of all parotid neoplasms. ${ }^{1}$ It is a slow-growing benign neoplasm, most commonly seen as a solitary lesion. Histologically, it is characterized by the presence of cellular pleomorphism and is composed of an epithelial and connective tissue component within a stroma of mucoid, myxoid, chondroid, and osteoid origin. ${ }^{2}$ The tumor is surrounded by a delicate and incomplete pseudocapsule and often has microscopic fingerlike projections into the surrounding parotid tissue. This fact may help explain why the historic technique of enucleation of the tumor with minimal exposure and no margin of normal tissue led to a rate of recurrence between $20 \%$ and $45 \%$. $^{3,4}$ Presently, various extents of parotidectomy with identification and preservation of the facial nerve are the procedures of choice for treatment of pleomorphic adenomas. ${ }^{5}$ This has decreased the rate of recurrence to $1 \%-4 \%$ during the past several decades, though the rate of recurrence is still not well documented. ${ }^{4}$

Recurrences usually occur within the first 10 years following initial surgery, and rarely, recurrences have been reported as long as 45 years after the initial surgery. ${ }^{6-8}$ The major risk factors for recurrence of benign mixed tumors include enucleation and rupture of the tumor at the time of surgical resec-

Received November 9, 2006; accepted after revision January 20, 2007.

From the Department of Radiology (G.M., P.P., L.A.L.), Neuroradiology Division, and the Department of Otorhinolaryngology (J.N.), Hospital of the University of Pennsylvania, Philadelphia, Pa; and Temple University School of Medicine (Y.K.), Philadelphia, Pa.

Scientific poster previously presented at: 44th Annual Meeting of the American Society of Neuroradiology; April 29-May 5, 2006, San Diego, Calif.

Please address correspondence to Gul Moonis, MD, Department of Radiology, Beth Israel Deaconess Medical Center, 300 Brookline Ave, Boston, MA 02215; e-mail: gmoonis@bidmc.harvard.edu

DOI 10.3174/ajnr.A0598 tion. ${ }^{9}$ Other associations for increased risk of recurrence include hypocellular tumors, ${ }^{10}$ younger age at initial presentation, ${ }^{11}$ female patients, ${ }^{12}$ and tumors that have already recurred. ${ }^{13,14}$

Management recommendations for recurrent tumors include observation, local or extensive surgery, radiation therapy, or a combination of these. ${ }^{12,14-17}$ Recurrences are often extensive and multifocal, making the risk of facial nerve damage and re-recurrence high. ${ }^{8,12,18}$ Malignant transformation to carcinoma is a well-known entity, and the literature reports a rate of between $1.4 \%$ and $6.3 \%$ in the larger series of patients. ${ }^{19}$ The risk of malignant transformation seems to be higher in patients older than 40 years of age, men, and patients with solitary nodules over $2 \mathrm{~cm}^{8}$ The risk of malignancy has also been linked to the frequency of recurrence. ${ }^{14,20}$

Although recurrent parotid pleomorphic adenomas have been the subject of much attention in the clinical literature, especially pertaining to management issues, there is a relative paucity of information defining the imaging characteristics of these lesions in the radiologic literature. ${ }^{15,21-23}$ Multiplicity of lesions has been described as a reliable indicator of recurrence in the parotidectomy bed of patients with prior pleomorphic adenoma resection. ${ }^{21}$ In the present study, we reviewed our institutional experience with imaging of recurrent parotid pleomorphic adenomas. We describe a spectrum of findings in patients with recurrent pleomorphic adenoma of the parotid gland and emphasize the importance of recognizing tiny (subcentimeter) lesions.

\section{Materials and Methods}

At our institution, approval from the institutional review board (IRB) is required for imaging and clinical chart review, even for retrospective studies. Approval was obtained from the IRB for the study. Contrast-enhanced MR images of the neck (21 patients) and contrast- 


\begin{tabular}{|c|c|c|c|c|c|c|}
\hline \multicolumn{7}{|c|}{ Recurrent pleomorphic adenomas of the parotid gland } \\
\hline Patient & Age/Sex & $\begin{array}{l}\text { Time after Initial } \\
\text { Surgery (y) }\end{array}$ & Site of Recurrence & No. Lesions & $\begin{array}{c}\text { Size of } \\
\text { Lesions }(\mathrm{mm})\end{array}$ & T2 Signal/Enhancement Characteristics \\
\hline 1 & $35 / F$ & 16 & Angle of mandible, deep lobe & 1 & 20 & T2 HI, peripheral enhancement \\
\hline 2 & $54 / F$ & 4 & $\begin{array}{l}\text { Superficial parotid, subcutaneous } \\
\text { tissue op bed }\end{array}$ & 1 & 9 & T2 isointense, solid enhancement \\
\hline 3 & $38 / F$ & 4 & Inferior parotid gland & 1 & 18 & T2 HI, no enhancement \\
\hline 4 & $49 / F$ & 25 & Inferior parotid gland & 2 & $2-20$ & T2 HI, no enhancement \\
\hline 5 & $62 / M$ & 7 & Superficial parotid & 1 & 14 & $\mathrm{~T} 2 \mathrm{HI}$, peripheral enhancement \\
\hline 6 & $32 / F$ & 18 & $\begin{array}{l}\text { Subcutaneous tissue op bed, } \\
\text { superficial to masseter }\end{array}$ & 1 & 30 & $\mathrm{~T} 2 \mathrm{HI}$, peripheral enhancement \\
\hline 7 & $63 / F$ & 21 & $\begin{array}{l}\text { Multiloculated lesion, superficial } \\
\text { parotid }\end{array}$ & 2 & $10-20$ & T2 HI, solid and peripheral enhancement \\
\hline 8 & $62 / M$ & 23 & $\begin{array}{l}\text { Preauricular mass, subcutaneous } \\
\text { tissue op bed }\end{array}$ & 2 & $10-25$ & T2 HI, heterogeneous enhancement \\
\hline 9 & $37 / F$ & 10 & $\begin{array}{l}\text { Preauricular mass, subcutaneous } \\
\text { tissue op bed }\end{array}$ & 2 & $8-15$ & $\mathrm{CT}$, smooth margin, enhancing lesions \\
\hline 10 & $59 / M$ & 6 & Superficial parotid & 1 & 19 & $\mathrm{CT}$, single smooth margin, enhancing lesion \\
\hline 11 & $47 / F$ & 25 & $\begin{array}{l}\text { Multiloculated lesion, superficial } \\
\text { parotid }\end{array}$ & 2 & $30-40$ & T2 HI, peripheral enhancement \\
\hline 12 & $63 / F$ & 24 & $\begin{array}{l}\text { Deep parotid, parapharyngeal } \\
\text { space, parotid tail, } \\
\text { submandibular space, carotid } \\
\text { sheath, subcutaneous tissue op } \\
\text { bed }\end{array}$ & Multiple & $4-22$ & CT, smooth margin, nonenhancing lesions \\
\hline 13 & $47 / F$ & 8 & Superficial parotid & 2 & $2-9$ & $\begin{array}{l}\text { T2 intermediate to hypointense, peripheral } \\
\text { enhancement }\end{array}$ \\
\hline 14 & $40 / M$ & 34 & $\begin{array}{l}\text { Superficial parotid, subcutaneous } \\
\text { tissue op bed, parotid tail }\end{array}$ & Multiple & $3-8$ & $\begin{array}{l}\text { T2 HI, solid (smaller lesions) and peripheral } \\
\text { enhancement (largest lesion) }\end{array}$ \\
\hline 15 & $55 / M$ & 35 & $\begin{array}{l}\text { Multiloculated lesion, superficial } \\
\text { parotid, superficial to masseter, } \\
\text { subcutaneous tissue op bed, } \\
\text { subcutaneous tissue inferior to } \\
\text { tail of parotid }\end{array}$ & Multiple & $2-30$ & $\begin{array}{l}\mathrm{T} 2 \mathrm{HI} \text {, heterogeneous enhancement, peripheral } \\
\text { enhancement in smallest lesion }\end{array}$ \\
\hline 16 & $41 / \mathrm{M}$ & 5 & Superficial parotid & 1 & 23 & $\mathrm{~T} 2 \mathrm{HI}$, heterogeneous enhancement \\
\hline 17 & $29 / F$ & 10 months & $\begin{array}{l}\text { Deep parotid, stylomastoid } \\
\text { foramen, parapharyngeal space, } \\
\text { subcutaneous tissue op bed, } \\
\text { postauricular subcutaneous } \\
\text { tissue }\end{array}$ & Multiple & $4-13$ & T2 HI, peripheral enhancement \\
\hline 18 & $58 / F$ & 40 & Subcutaneous tissue op bed & 2 & $2-6$ & T2 HI, no enhancement \\
\hline 19 & $31 / M$ & 10 & $\begin{array}{l}\text { Multiloculated lesion, superficial } \\
\text { parotid, parapharyngeal space, } \\
\text { subcutaneous tissue op bed }\end{array}$ & Multiple & $4-10$ & $\mathrm{~T} 2 \mathrm{HI}$, peripheral enhancement \\
\hline 20 & $55 / F$ & 22 & $\begin{array}{l}\text { Multiloculated lesion, superficial } \\
\text { parotid, deep parotid, } \\
\text { stylomastoid foramen, } \\
\text { subcutaneous tissue op bed, } \\
\text { parapharyngeal space, below tail } \\
\text { of parotid }\end{array}$ & Multiple & $5-15$ & $\mathrm{~T} 2 \mathrm{HI}$, peripheral enhancement \\
\hline 21 & $46 / M$ & 6 & $\begin{array}{l}\text { Superficial parotid, deep parotid, } \\
\text { parapharyngeal space, } \\
\text { subcutaneous tissue op bed }\end{array}$ & Multiple & $4-40$ & T2 Hl, postgad images, nondiagnostic \\
\hline 22 & $48 / F$ & 21 & Superficial parotid & 1 & 6 & $\begin{array}{l}\text { T2 isointense to parotid, hypointense on } \mathrm{T} 1 \text {, solid } \\
\text { enhancement }\end{array}$ \\
\hline 23 & $49 / M$ & 24 & $\begin{array}{l}\text { Superficial parotid, subcutaneous } \\
\text { tissue op bed }\end{array}$ & Multiple & $1-12$ & T2 HI, both solid and peripheral enhancement \\
\hline 24 & $60 / F$ & 5 & $\begin{array}{l}\text { Superficial parotid, subcutaneous } \\
\text { tissue op bed }\end{array}$ & 3 & $12,7,7$ & T2 HI, peripheral enhancement \\
\hline
\end{tabular}

Note:-T2 HI indicates T2 hyperintense relative to the normal parotid; op bed, indicates operative bed; postgad, postgadolinium.

enhanced CT scans of the neck ( 3 patients) in 24 patients ( 9 men, 15 women; age, 29-63 years) with recurrent pleomorphic adenoma of the parotid gland were retrospectively reviewed as to lesion margins, site, multiplicity, signal intensity, and enhancement pattern by 2 neuroradiologists. All patients had initially undergone surgery ranging from enucleation to partial parotidectomy to complete parotidec- tomy for pleomorphic adenoma from 11 months to 40 years before recurrence. Recurrence was proved pathologically in all patients.

\section{Results}

Both solitary and multiple lesions were seen. Multiple lesions were seen in 16/24 (66\%) patients (Table). All recurrent nod- 

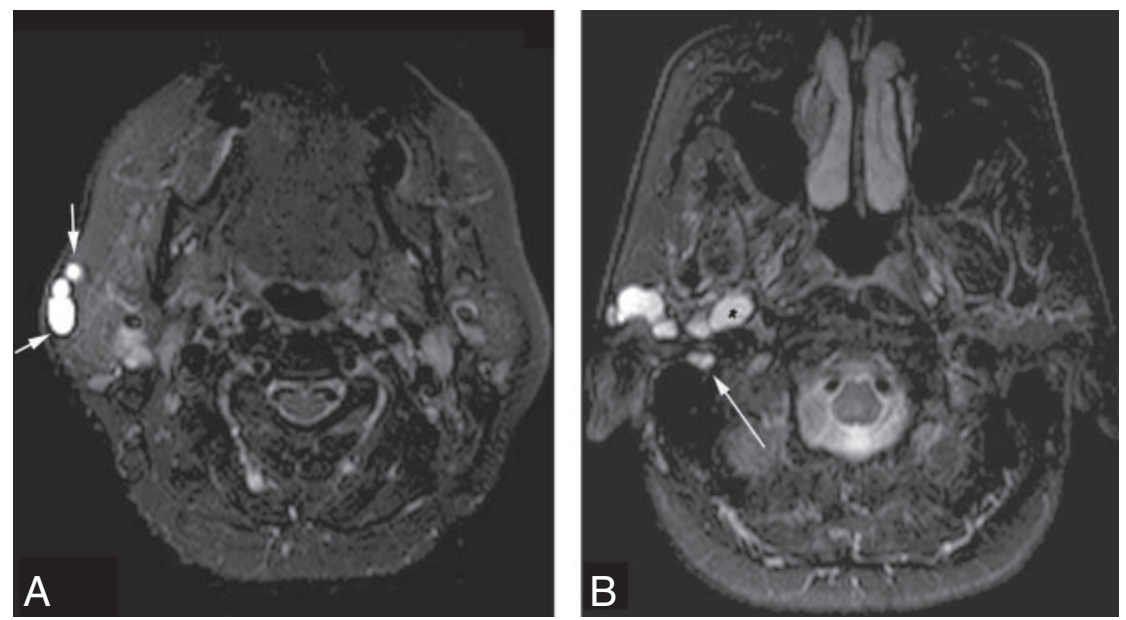

Fig 1. A, 55-year-old woman who underwent superficial parotidectomy 22 years before recurrence. Axial fat-suppressed T2-weighted MR image demonstrates marked T2 hyperintensity of multiple recurrent pleomorphic adenoma lesions on the right. Subcutaneous location of lesions is also noted on this image (arrows). B, Also noted are multiple T2 hyperintense recurrent lesions at the right stylomastoid foramen (white arrow), the right parapharyngeal space (asterisk), and the superficial parotidectomy bed on this axial fat-suppressed T2-weighted MR image.

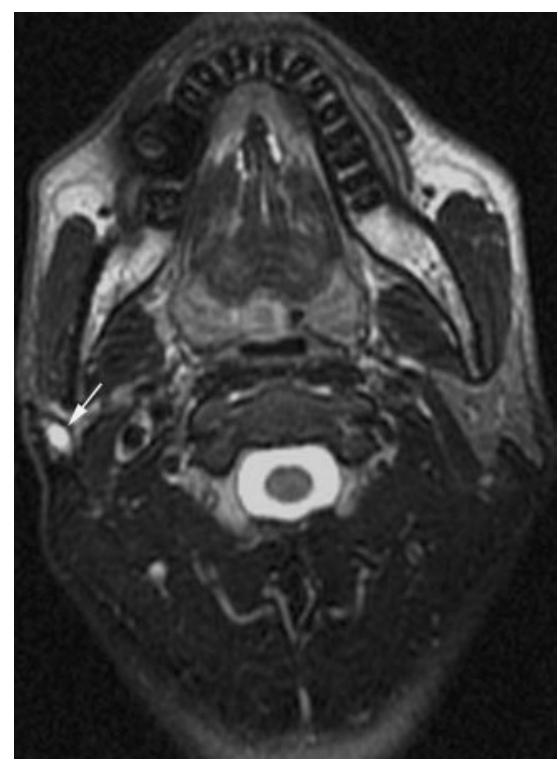

Fig 2. A 40-year-old man with near-total right parotidectomy performed 34 years previously. There is marked T2 hyperintensity in a tiny recurrent pleomorphic adenoma lesion (arrow). ules were well circumscribed with smooth margins. On MR imaging, marked hyperintensity on T2-weighted images was noted in $18 / 21(85 \%)$ patients (Figs 1 and 2). Three patients had lesions that were iso- to hypointense on T2-weighted images relative to the normal parotid tissue. There was a variable pattern of enhancement, ranging from peripheral enhancement (9/21 patients) (Fig 3 ) to solid enhancement (2/21 patients) to mixed heterogeneous solid and peripheral enhancement (6/21 patients) (Fig 4B). There was no enhancement in $3 / 21$ patients. Gadolinium-enhanced images were nondiagnostic in 1 patient. Five patients had large infiltrative multiloculated T2 hyperintense lesions, of which 3 demonstrated peripheral enhancement and 2 demonstrated both peripheral and solid enhancement (Fig 4). The 3 patients who underwent enhanced CT imaging demonstrated marginated solidly enhancing lesions. Recurrent nodules in the subcutaneous tissue were seen in $14 / 24$ patients (Figs $1 A$ and 5). Several of the lesions were tiny, ranging from 2 to $6 \mathrm{~mm}$ (13/24 patients) (Figs 1 and 2). Lesions were not confined to the parotid but were seen in areas distant from the operative bed, including the postauricular region, the masticator space, the parapharyngeal space, and inferior to the parotid tail along the carotid sheath (7/24 patients) (Figs $1 B$ and 6).

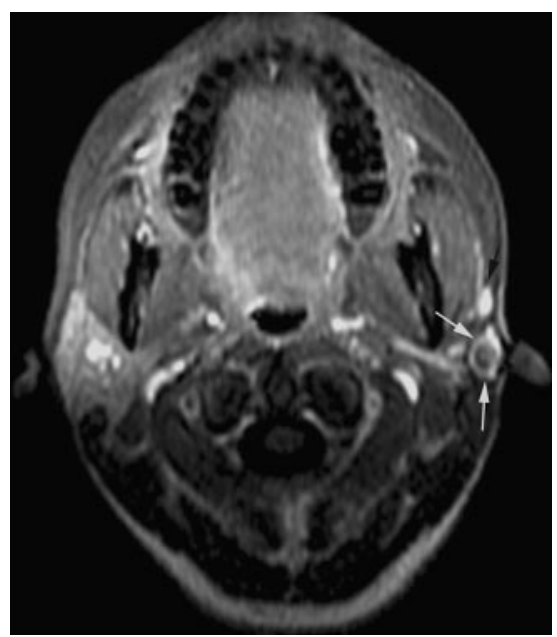

Fig 3. A 47-year-old woman 8 years after superficial parotidectomy. Axial gadolinium-enhanced fat-suppressed T1-weighted image through the neck shows rim enhancement of the recurrent nodule in the left superficial parotidectomy bed (arrows). The small enhancing structure anterior to the nodule is a vein (black arrow).

\section{Discussion}

Histopathologically, pleomorphic adenomas are divided into 3 types: myxoid (or stroma-rich), cellular, and classic types. Myxoid or hypocellular tumor is the most common subtype, which also demonstrates the highest incidence of capsular thinning or areas of capsular absence and pseudopodia formation, ${ }^{10}$ leading to increased propensity for recurrence. Recurrences are more likely in patients who develop the primary tumor at an earlier age; the reason for this is not entirely clear. $^{11}$

Some variation of segmental parotidectomy with facial nerve dissection is the standard surgical approach to treat pleomorphic adenomas of the parotid gland. Enucleation of the tumor yielded the highest recurrence rate $(30 \%)$ and is no longer a treatment option. ${ }^{16,24,25}$ When the capsule is ruptured during superficial parotidectomy with facial nerve dissection, the rate of recurrence is $5 \% .{ }^{5}$ Our hospital is a large tertiary care center for head and neck cancer, and most of the patients in our study were referred from peripheral medical centers. Therefore, we were unable to obtain details of the type of initial parotid surgery performed in many of these patients.

Multiplicity of recurrent pleomorphic adenomas is well described in the ear, nose, and throat (ENT) literature. ${ }^{6,14,15,26,27}$ Multiple lesions have been shown to be an indicator of recurrence in a prior imaging study. ${ }^{21}$ In our study, we found multiplicity of lesions in 16/24 (66\%) patients, which is in keeping with prior imaging and ENT literature. ${ }^{15,21,23}$ The presence of 

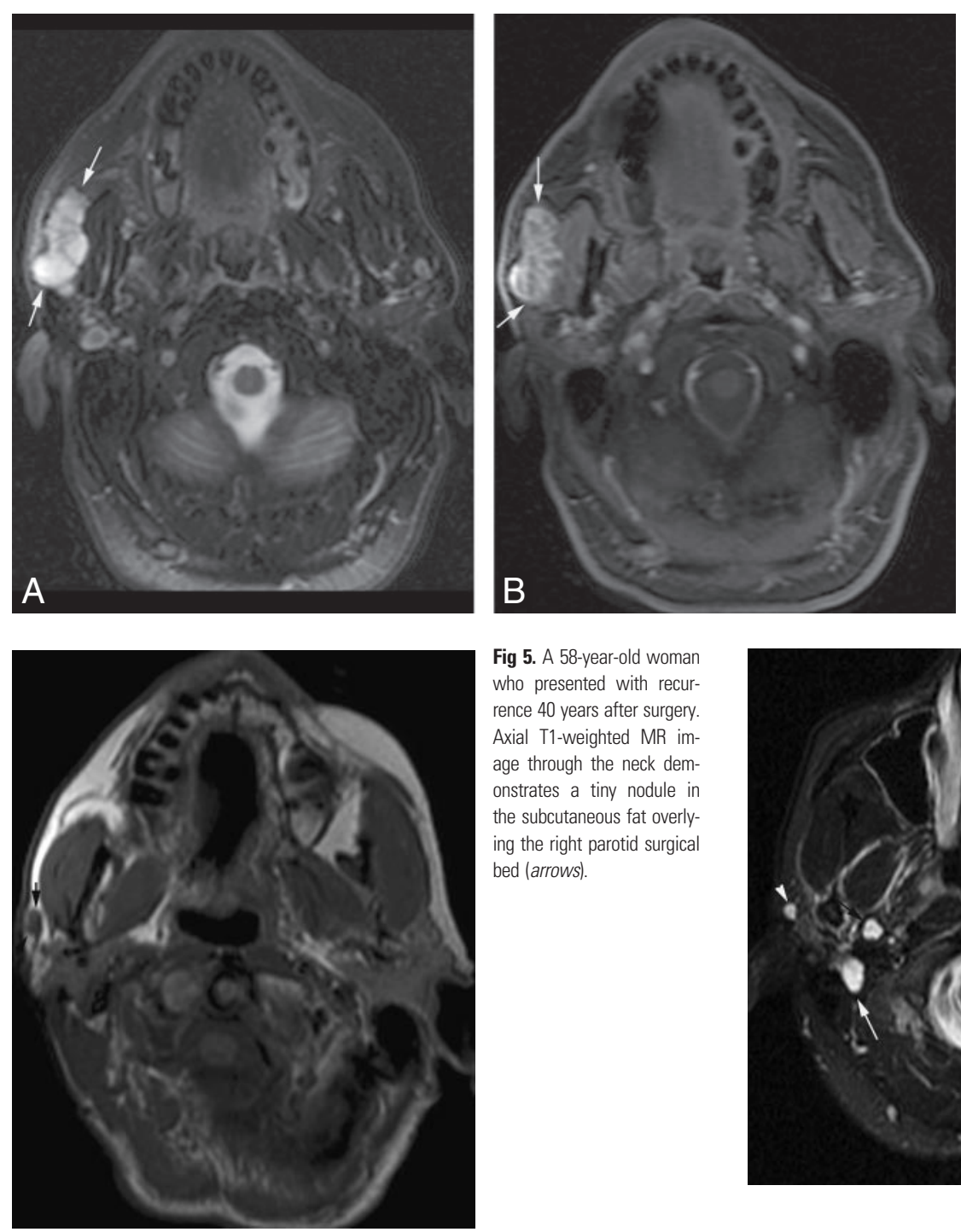

Fig 5. A 58-year-old woman who presented with recurrence 40 years after surgery. Axial T1-weighted MR image through the neck demonstrates a tiny nodule in the subcutaneous fat overlying the right parotid surgical bed (arrows).

multinodular recurrence is probably related to pseudocapsular tear and inadvertent tumor spillage. ${ }^{3,9}$ Microscopic disease beyond capsular margins and multifocal disease are also implicated in recurrence of benign mixed tumors. ${ }^{14} \mathrm{We}$ found a fair number of lesions in the subcutaneous tissue and in locations distant from the surgical bed, probably related to tumor spillage during surgery. Some of these lesions were quiet small but were symptomatic, leading to imaging detection directed by clinical examination/palpation. This correlates with reported histopathologic findings of numerous submillimeter nodules in recurrent lesions. ${ }^{28}$ The clinical presentation of patients with recurrent pleomorphic adenoma of the parotid gland includes multiple nontender lesions in the prior surgical bed, which are slow-growing and often underestimated by palpation. ${ }^{29}$ At our institution, routine imaging surveillance is performed after surgery for pleomorphic adenoma, and in 1 of our patients, the lesion was clinically occult and detected only on follow-up imaging. Another lesion was detected on imaging of the neck performed for unrelated indications. The recurrent tumors were almost universally hyperintense on T2weighted images, recapitulating the imaging characteristics of the original tumor.

Most pleomorphic adenomas are very bright on T2series. $^{23}$

\section{Conclusion}

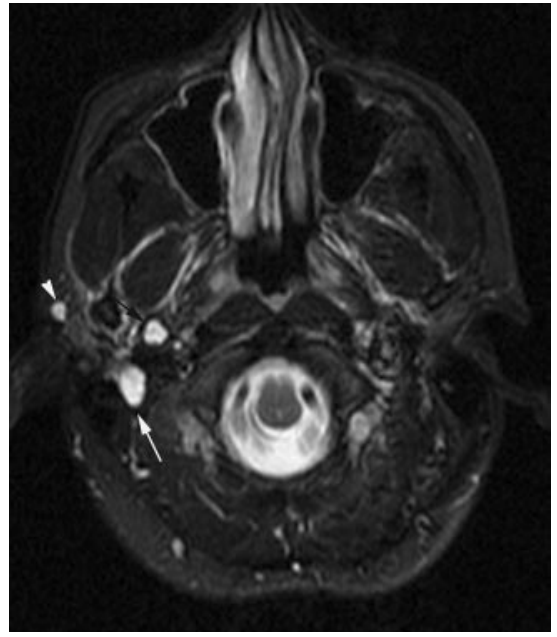

Fig 6. A 29-year-old woman 10 months after superficial parotidectomy. Axial fatsuppressed T2-weighted MR image demonstrates $\mathrm{T} 2$ hyperintense recurrent lesions in the right parapharyngeal space (black arrow), in the stylomastoid foramen (white arrow), and in the subcutaneous tissue anteriorly (white arrowhead)

weighted images due to presence of myxoid material. ${ }^{30}$ The myxoid subtype has been shown to be the predominant subtype in recurrent pleomorphic adenomas. ${ }^{28}$ Cystic-appearing nodules with peripheral enhancement were seen in 8 patients. Five patients had large infiltrative multiloculated T2 hyperintense lesions with both peripheral and solid enhancement. These patients had remote surgery ranging from 10 to 35 years (mean, 22.6 years) before presentation. The long time interval between initial surgery and recurrence presumably allowed these lesions to attain a sizeable volume. Two patients had T2 hypointense lesions with peripheral enhancement, which likely reflected the high proteinaceous content of the recurrent cystic lesions. The enhancement pattern of recurrent nodules was variable, ranging from solid and homogeneous to heterogeneous to rim enhancement (cystic pattern). Heterogeneous enhancement is likely due to areas of fibrosis and necrosis. In our series, no bony destruction or calcification was noted with the recurrent lesions, though this was described in a prior case

In conclusion, we present the spectrum of imaging findings seen in recurrent pleomorphic adenomas. The presence of solitary and especially multiple subcutaneous nodules, or T2 hy- 
perintense lesions spanning multiple spaces adjacent to the parotid/operative bed in patients with prior parotidectomy for pleomorphic adenoma, should suggest the diagnosis of recurrence. Although most imaging studies are guided by clinical examination, the radiologist should maintain a high index of suspicion for this entity even if a surgical history is lacking because evidence of tumor enucleation is usually undetectable on imaging.

\section{References}

1. Spiro RH. Salivary neoplasms: overview of a 35 -year experience with 2,807 patients. Head Neck Surg 1986;8:177-84

2. Woods JE, Weiland LH, Chong GC, et al. Pathology and surgery of primary tumors of the parotid. Surg Clin North Am 1977;57:565-73

3. Donovan DT, Conley JJ. Capsular significance in parotid tumor surgery: reality and myths of lateral lobectomy. Laryngoscope 1984;94:324-29

4. Leverstein H, van der Wal JE, Tiwari RM, et al. Surgical management of 246 previously untreated pleomorphic adenomas of the parotid gland. Br J Surg 1997;84:399-403

5. Witt RL. The significance of the margin in parotid surgery for pleomorphic adenoma. Laryngoscope 2002;112:2141-54

6. Renehan A, Gleave EN, McGurk M. An analysis of the treatment of 114 patients with recurrent pleomorphic adenomas of the parotid gland. Am J Surg 1996;172:710-04

7. Naeim F, Forsberg MI, Waisman J, et al. Mixed tumors of the salivary glands: growth pattern and recurrence. Arch Pathol Lab Med 1976;100:271-75

8. Phillips PP, Olsen KD. Recurrent pleomorphic adenoma of the parotid gland: report of 126 cases and a review of the literature. Ann Otol Rhinol Laryngol 1995;104:100-04

9. McGurk M, Renehan A, Gleave EN, et al. Clinical significance of the tumour capsule in the treatment of parotid pleomorphic adenomas. Br J Surg 1996;83:1747-49

10. Stennert E, Guntinas-Lichius O, Klussmann JP, et al. Histopathology of pleomorphic adenoma in the parotid gland: a prospective unselected series of 100 cases. Laryngoscope 2001;111:2195-200

11. McGregor AD, Burgoyne M, Tan KC. Recurrent pleomorphic salivary adenoma: the relevance of age at first presentation. Br J Plast Surg 1988;41:177-81
12. Myssiorek D, Ruah CB, Hybels RL. Recurrent pleomorphic adenomas of the parotid gland. Head Neck 1990;12:332-36

13. Gleave EN, Whittaker JS, Nicholson A. Salivary tumours: experience over thirty years. Clin Otolaryngol Allied Sci 1979;4:247-57

14. Carew JF, Spiro RH, Singh B, et al. Treatment of recurrent pleomorphic adenomas of the parotid gland. Otolaryngol Head Neck Surg 1999;121:539-42

15. Leonetti JP, Marzo SJ, Petruzzelli GJ, et al. Recurrent pleomorphic adenoma of the parotid gland. Otolaryngol Head Neck Surg 2005;133:319-22

16. Maynard JD. Management of pleomorphic adenoma of the parotid. Br J Surg 1988;75:305-08

17. Chen AM, Garcia J, Bucci MK, et al. Recurrent pleomorphic adenoma of the parotid gland: long-term outcome of patients treated with radiation therapy. Int J Radiat Oncol Biol Phys 2006;66:1031-35

18. Maran AG, Mackenzie IJ, Stanley RE. Recurrent pleomorphic adenomas of the parotid gland. Arch Otolaryngol 1984;110:167-71

19. Maxwell EL, Hall FT, Freeman JL. Recurrent pleomorphic adenoma of the parotid gland. J Otolaryngol 2004;33:181-84

20. Duck SW, McConnel FM. Malignant degeneration of pleomorphic adenoma: clinical implications. Am J Otolaryngol 1993;14:175-78

21. Koral K, Sayre J, Bhuta S, et al. Recurrent pleomorphic adenoma of the parotid gland in pediatric and adult patients: value of multiple lesions as a diagnostic indicator. AJR Am J Roentgenol 2003;180:1171-74

22. Som PM, Shugar JM, Sacher M, et al. Benign and malignant parotid pleomorphic adenomas: CT and MR studies. J Comput Assist Tomogr 1988;12:65-69

23. Yasumoto M, Sunaba K, Shibuya $\mathrm{H}$, et al. Recurrent pleomorphic adenoma of the head and neck. Neuroradiology 1999;41:300-04

24. Maynard JD. Enucleated parotid tumours. Br J Surg 1988;75:764-66

25. Niparko JK, Beauchamp ML, Krause CJ, et al. Surgical treatment of recurrent pleomorphic adenoma of the parotid gland. Arch Otolaryngol Head Neck Surg 1986;112:1180-84

26. Rowley H, Murphy M, Smyth D, et al. Recurrent pleomorphic adenoma: uninodular versus multinodular disease. Ir J Med Sci 2000;169:201-03

27. Zbaren P, Tschumi I, Nuyens M, et al. Recurrent pleomorphic adenoma of the parotid gland. Am J Surg 2005;189:203-07

28. Stennert E, Wittekindt C, Klussmann JP, et al. Recurrent pleomorphic adenoma of the parotid gland: a prospective histopathological and immunohistochemical study. Laryngoscope 2004;114:158-63

29. Work WP, Batsakis JG, Bailey DG. Recurrent benign mixed tumor and the facial nerve. Arch Otolaryngol 1976;102:15-19

30. Tsushima Y, Matsumoto M, Endo K, et al. Characteristic bright signal of parotid pleomorphic adenomas on $\mathrm{T} 2$-weighted $\mathrm{MR}$ images with pathological correlation. Clin Radiol 1994;49:485-89 